\title{
PEMODELAN SISTEM LAMPU OTOMATIS HEMAT ENERGI UNTUK RUANG KELAS TANPA PEMROGRAMAN
}

\author{
Yohanes Calvinus $^{1 *}$, Endah Setyaningsih ${ }^{2}$ \\ ${ }^{12}$ Jurusan Teknologi Industri, Program Studi Teknik Elektro, Universitas Tarumanagara \\ *Email:yohanesc@ft.untar.ac.id
}

Masuk: 02-05-2019, revisi: 10-09-2021, diterima untuk diterbitkan: 17-09-2021

\begin{abstract}
ABSTRAK
Lampu merupakan alat elektronika yang menghasilkan cahaya ternyata salah satu komponen dalam pengeluaran biaya listrik yang cukup besar. Semakin besar ruangan, maka ruang tersebut akan membutuhkan banyak lampu penerangan untuk mencapai nilai suatu tingkat pencahayaan yang sesuai Standard Nasional Indonesia (SNI) pada ruangan tersebut. Semakin banyak lampu yang digunakan tentu semakin boros energi yang digunakan. Boros energi maka pengeluaran untuk biaya operasional akan semakin besar. Peran teknologi dapat digunakan berdampingan dengan budaya hemat energi. Salah satu nya dengan sistem otomatisasi lampu. Sistem otomatisasi dapat direalisasikan tanpa pemrograman. berdasarkan survei tempat yang membutuhkan sistem otomatisasi ini adalah ruangan kelas sekolah. Sistem otomatisasi dapat langsung dipasangkan dengan sistem lampu dan saklar lampu manual di ruang kelas menggantikan sistem mati nyala lampu secara konvensional di ruang kelas. Pemasangannya yang mudah menjadikan contoh bagi pemasangan sistem otomatisasi bagi sekolah yang memiliki ruang kelas yang cukup banyak. Sensor otomatisasi yang digunakan merupakan jenis sensor yang memiliki cara kerja untuk mendeteksi pergerakan orang di dalam ruangan. Sensor yang dapat digunakan paling mudah yaitu sensor Passive Infra Red (PIR). Sensor PIR merupakan sensor yang paling mudah didapatkan dan cukup murah. Dalam realisasi penggunaan sensor ini diperlukan lebih dari 1 titik sensor PIR. Sensor yang digunakan lebih dari 1 titik akan membuat pengelompokkan bagian dari sistem pencahayaan di ruang kelas tersebut. Jika ruang kelas tidak digunakan sepenuhnya hingga bagian belakang kelas, maka cukup hanya dinyalakan dari lampu bagian depan hingga ruang tengah kelas. Hal ini mendukung upaya hemat energi. Melalui otomatisasi ini diharapkan ada perubahan budaya hemat energi yang berdampingan dengan perkembangan teknologi dalam hal pemanfaatannya untuk hemat energi.
\end{abstract}

Kata Kunci: LED; Sensor Gerak; Ruang kelas; tanpa program; sistem otomatis

\begin{abstract}
Lamps are electronic devices that produce light turned out to be one of the components in spending considerable electrical costs. The bigger the room, the space will require a lot of lighting to achieve the value of a lighting level according to the Indonesian National Standard (SNI) in the room. The more lamps that are used, the more wasteful the energy is used. Wasteful of energy, so the expenditure for operational costs will be even greater. The role of technology can be used alongside a culture of energy saving. One of them is a light automation system. Automation systems can be realized without programming. based on a survey the place that requires this automation system is a school classroom. Automation systems can be directly coupled with light systems and manual light switches in classrooms, replacing conventional light-on and off-turn systems in classrooms. Its easy installation provides an example for installing an automation system for schools that have a large number of classrooms. The automation sensor used is a type of sensor that has a way of detecting the movement of people in the room. The sensor that can be used the easiest is the Passive Infra Red (PIR) sensor. This sensor itself is the sensor that is most easily available and quite cheap. In realizing the use of this sensor, more than 1 PIR sensor point is required. Sensors that are used more than 1 point will make grouping part of the lighting system in the classroom. If the classroom is not fully used up to the back of the classroom, then it is enough only to turn it on from the front lights to the middle of the classroom. This supports energy saving efforts. Through this automation, it is hoped that there will be a change in the culture of energy saving side by side with technological developments in terms of its use for energy saving.
\end{abstract}

Keywords: LED; motion sensor; classroom; without programming; automation system 


\section{PENDAHULUAN}

\section{Latar belakang}

Lampu yang menghasilkan pencahayaan adalah suatu teknologi yang saat ini telah menjadi suatu kebutuhan dalam kehidupan sehari-hari. Tanpa lampu akan banyak aktifitas keseharian yang akan terganggu. Penggunaan Lampu ini menjadi salah satu pengeluaran terbesar biaya listrik yang tidak terduga besar biayanya. Lampu di sekolah merupakan salah satu fasilitas terpenting agar setiap siswa/i di sekolah dapat nyaman belajar di kelas. Berdasasrkan standard nasional indonesia, tingkat pencahayaan di ruang kelas harus lebih kurang memiliki besar yaitu diatas 350 lux (Badan Standardisasi Nasional, 2000). Pencapaian tingkat pencahayaan yang memenuhi standard SNI ini, jumlah lampu yang digunakan tentu akan sebanding dengan besarnya ruang kelas yang akan digunakan. Penjelasannya seperti ini yaitu apabila ruang semakin besar, maka jumlah lampu yang dibutuhkan untuk mencapai standard diatas 350 lux tersebut akan semakin banyak.

Teknologi lampu saat ini yang dipergunakan yaitu teknologi LED yang memiliki sifat terang yang dipancarkan akan lebih tinggi daripada penggunaan energinya. Secara singkat kata teknologi LED lebih hemat daya dan menghasilkan tingkat pencahayaan (lumens) lebih besar (DiLaura DL, Houser KW, Mistrick RG, 2011). Penghematan energi sangat diperlukan dimana kita ketahui energi lampu yang sudah terkonversikan menjadi cahaya hingga saat ini belum dapat diolah lagi menjadi suatu energi lainnya. Energi cahaya merupakan suatu energi akhir yang terbuang pada saat digunakan. Perilaku hemat energi sangat diperlukan mengingat bahwa energi cahaya yang akan terbuang percuma. Pepatah mengatakan hemat pangkal kaya, maka melalui pepatah tersebut dengan menghemat energi listrik yang diubah menjadi energi cahaya tentu akan membantu dalam menghemat biaya listrik yang dikeluarkan. Dampak hemat energi secara global di suatu negara yaitu dengan menghemat energi maka energi tersebut dapat dipergunakan untuk hal lainnya sehingga pemerintah tidak perlu membangun infrastruktur pembangkit energi berlebihan.

Menurut survei di lapangan, ruangan perkantoran dan ruang kelas pada tempat pendidikan memiliki bagian besar hingga diatas 30\% penggunaan konsumsi listrik untuk pencahayaan. Hal ini dikarenakan pada jam aktif pada umumnya lampu pada ruangan dinyalakan sebagai tanda ruangan tersebut digunakan meskipun pada kenyataannya ruangan tersebut tidak sepenuhnya digunakan selama jam aktif kerja. Ruang kelas dan ruang kantor memiliki standar lux yang hampir sama yaitu sekitar 300 lux hingga 350 lux (Badan Standardisasi Nasional, 2000; Widodo et al., 2015). Dalam penelitian ini dilakukan kerjasama juga dengan sekolah SMPN 02 Cibinong sebagai tempat realisasi objek penelitian. SMPN 02 Cibinong menyediakan sebuah ruangan untuk bisa menjadi objek penelitian dengan ruangan 9 meter x 7 meter. Untuk mendapatkan kurang lebih antara 300 lux hingga 350 lux pada ruangan yang berukuran 9 meter x 7 meter dengan ketinggian 3 meter dibutuhkan lampu sebanyak 18 lampu @ 18 watt LED technology sehingga total sebesar 324 watt (tampak pada Gambar 1). 

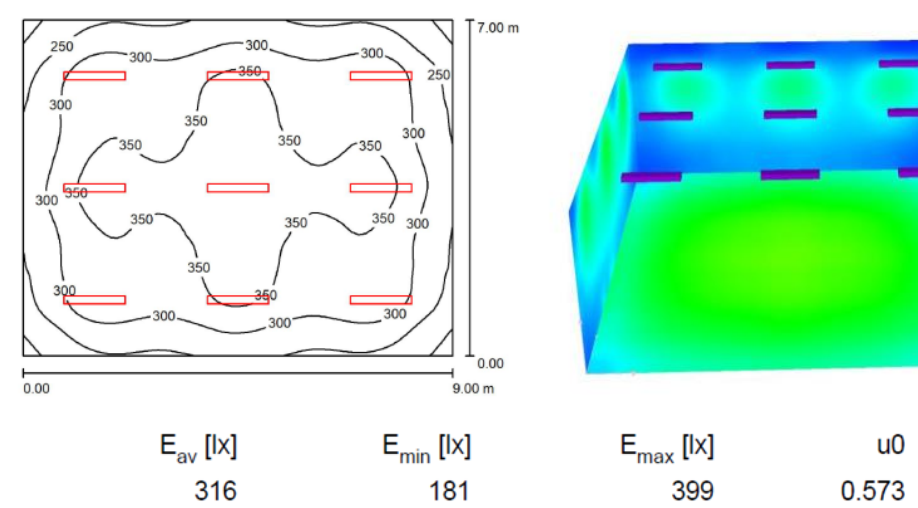

Gambar 1. SNI Desain Lampu di Ruang kelas di SMPN 02 Cibinong 9x7x3 Meter

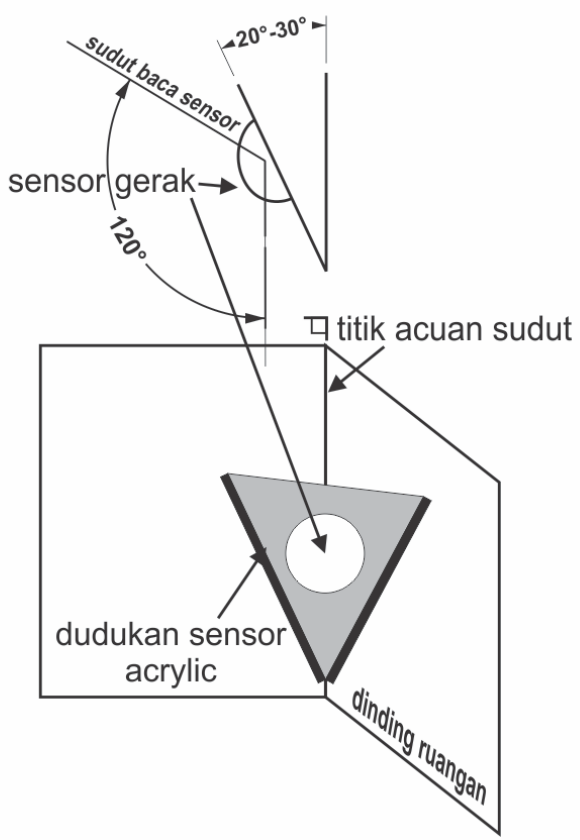

Gambar 2. Posisi Penempatan Sensor Gerak untuk mendeteksi Vertikal Movement

Penggunaan Lampu dengan daya sebesar 324 watt memakan cukup besar energi listrik yang dipergunakan ditambahkan apabila lampu tersebut dibiarkan menyala dalam keadaan ruang tidak terpakai. Salah satu nya dengan menghemat energi dengan mematikan lampu tersebut pada saat ruangan tidak digunakan, semisalkan pada saat jam beristirahat (tidak ada orang di dalam kelas) ataupun pada saat jam berolahraga. Dengan Sensor Gerak mendeteksi dengan ada nya pergerakan di dalam ruangan (Badan Standardisasi Nasional, 2000; Wilson, 2005), berarti ruangan sedang digunakan dan ada nya kegiatan yang dilakukan pada ruangan tersebut (Widodo et al., 2015).

Agar akurasi dalam pembacaan pergerakan di dalam ruangan, maka sensor gerak tidak dapat serta merta ditaruh pada ruangan secara top to bottom. Pergerakan manusia lebih umumnya adalah pergerakan secara vertikal dengan contoh menggerakan kepala, mengacungkan tangan, berdiri dan lain-lain nya. Sensor gerak yang ditaruh pada top to bottom hanya dapat mendeteksi pergerakan secara horizontal yang arti pergerakan dibaca apabila ada pergerakan dari belakang ruangan ke depan ruangan maupun secara acak dengan pengertian orang di dalam ruangan tersebut tidak berdiam pada satu titik melainkan berpindah dari satu titik ke titik lainnya. Untuk ruang kelas yang 
pada penggunaan nya lebih banyak dilakukan dengan kegiatan belajar mengajar dimana siswa dan guru berdiam pada bangku dan lebih banyak pergerakan yang sifat nya statis (vertikal), maka sensor akan ditaruh dengan sudut kemiringan tertentu pada dinding ruang untuk mendeteksi pergerakan secara vertikal. Sensor memiliki sudut baca sebesar 120 derajat, penempatan sensor terhadap ruangan pada sudut siku ruangan sebesar antara 20 hingga 30 derajat. Terlihat pada Gambar 2.

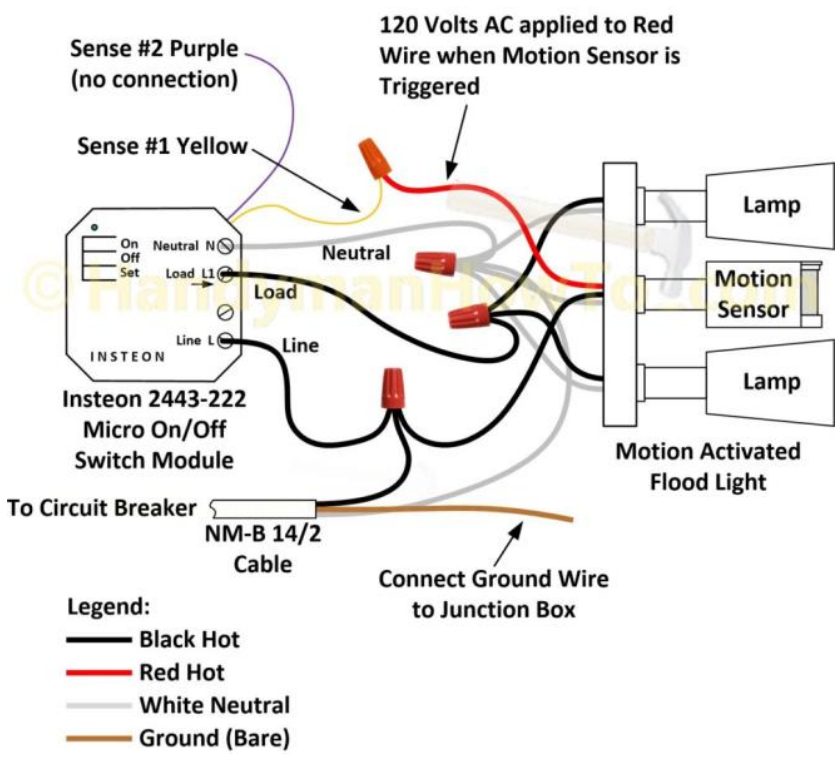

Gambar 3. Pemasangan Kabel antara Sensor Gerak dan Lampu
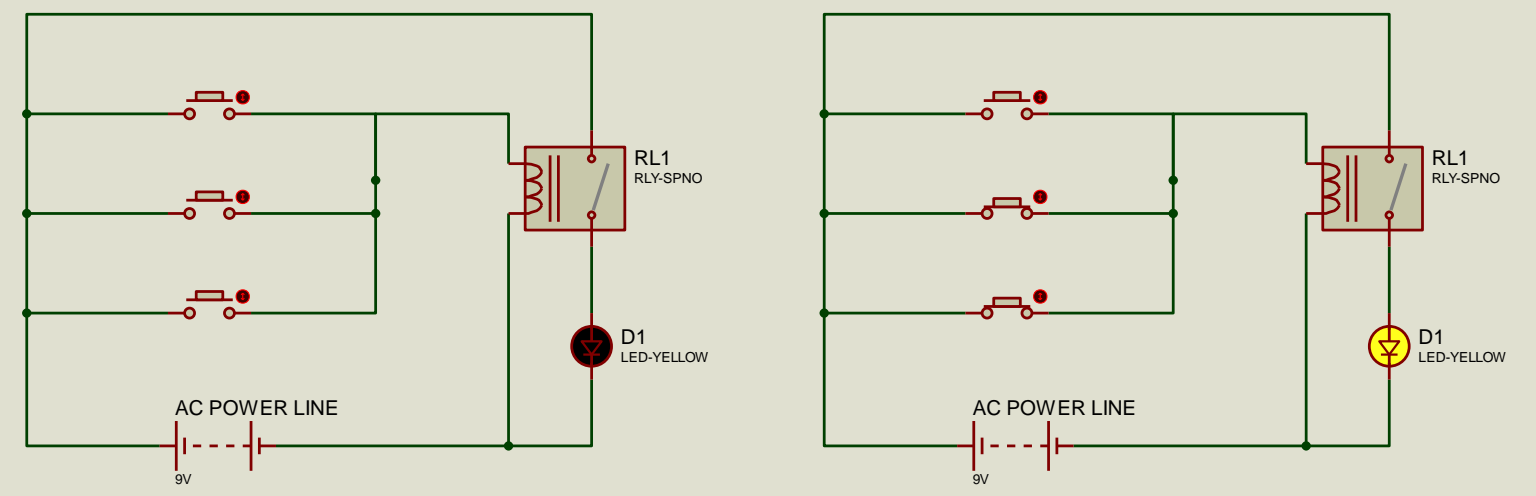

Gambar 4. Ilustrasi Pemasangan Sensor Gerak Sebagai Saklar dengan Relay seri NO

Pada pemasangan antara sensor gerak dengan lampu tentu nya memiliki konfigurasi pemasangan yang tampak pada Gambar 3. Modul sensor gerak terdapat port untuk sumber tegangan, keluaran untuk lampu yang dapat di paralel baik antara sensor gerak dan lampu. Jumlah pemasangan sensor pada suatu ruangan bisa saja lebih dari satu buah sensor gerak. Hal ini memanfaatkan peluang yang terdapat pada konsep saklar yang di paralel antara sensor gerak. Dengan penjelasan pada Gambar 4. Semoga konsep pemasangan sensor gerak dapat dimengerti. 
Secara peluang dan perhitungan tampak pada tabel 1. Dimana peluang untuk mematikan lampu akan semakin kecil apabila dipergunakan 3 buah sensor seperti pada tabel 1. Peluang untuk kondisi lampu mati hanya sebesar 1/8 dari kemungkinan sensor mendeteksi pergerakan.

Tabel 1. Peluang kondisi lampu mati dengan 3 buah Sensor

\begin{tabular}{cccc}
\hline sensor 1 & sensor 2 & sensor 3 & output \\
\hline OFF & OFF & OFF & Lampu Mati \\
\hline OFF & OFF & ON & Lampu Nyala \\
\hline OFF & ON & OFF & Lampu Nyala \\
\hline OFF & ON & ON & Lampu Nyala \\
\hline ON & OFF & OFF & Lampu Nyala \\
\hline ON & OFF & ON & Lampu Nyala \\
\hline ON & ON & OFF & Lampu Nyala \\
\hline ON & ON & ON & Lampu Nyala \\
\hline
\end{tabular}

\section{METODE PELAKSANAAN}

Metode pelaksanaan yang dilakukan dalam ini dengan membuat bentuk uji coba protitpe dan kemudian dilanjutkan dengan realisasi di lapangan sebenarnya di sekolah SMPN 02 cibinong. Uji coba prototipe dilakukan didalam ruang laboratorium program studi teknik elektro yang dilakukan bersama dengan pendamping penanggung jawab ruangan. Sebelum direalisasikan di lapangan maka sistem diuji coba dahulu di ruangan kelas program studi teknik elektro di Universitas Tarumanagara dalam bentuk rancangan prototipe. Dari hasil perancangan serta pengukuran pada sensor gerak yang dilakukan pada ruangan kelas kuliah pada ruangan yang berukuran 7 meter x 7 meter yang ditempatkan pada sudut ruang untuk mencari pola baca dan pengukuran. Hasil dari pengukuran di tabulasikan ke dalam tabel 2. Dan pembacaan efektif dilakukan dengan menggunakan 3 pcs sensor gerak yang ditempatkan pada sudut ruangan seperti tampak pada Gambar 5.

Dari hasil didapatkan pola sensor berbentuk seperti kerucut sehingga penempatan atau titik pada ruangan tidak sepenuh dapat di baca penuh oleh sensor gerak dengan sempurna (Fraden, 2016). Maksudnya dalam pembacaan sensor gerak ini tetap terdapat suatu blind spot atau yang disebut titik buta. Oleh karena itu sangat perlu penempatan sensor ditempatkan dengan baik untuk mendeteksi titik rawan pergerakan agar pembacaan sensor menjadi akurat. Untuk ruangan yang melebihi dari $7 \mathrm{~m} \times 7 \mathrm{~m}$ dibutuhkan lebih dari 3 sensor, ada baik nya ditempatkan lebih dari dengan aturan $(2 \mathrm{n}+1)$ maksudnya untuk ruangan $9 \mathrm{~m} \times 7 \mathrm{~m}$ ditempatkan sebanyak 7 buah sensor yang didapat dari perhitungan sebagai berikut : 2 ( 3 sensor dalam maks $\left.7 \times 7 \mathrm{~m}^{2}\right)+1=7$ sensor. 
Tabel 2. Tabel Hasil Ukur Sensor Gerak Maximum (satuan dalam meter)

\begin{tabular}{cccc}
\hline Uji Coba & $\mathbf{0}^{\circ}$ dari Titik Tengah & $\mathbf{1 5}^{\circ}$ dari Titik Tengah & $\mathbf{4 5}^{\circ}$ dari Titik Tengah \\
\hline 1 & 7,00 & 6,60 & 5,00 \\
\hline 2 & 6,80 & 6,50 & 5,10 \\
\hline 3 & 6,90 & 6,40 & 4,90 \\
\hline 4 & 7,00 & 6,60 & 5,00 \\
\hline 5 & 7,10 & 6,70 & 5,00 \\
\hline Rata2x & $\mathbf{6 , 9 6}$ & $\mathbf{6 , 5 6}$ & $\mathbf{5 , 0 0}$ \\
\hline
\end{tabular}
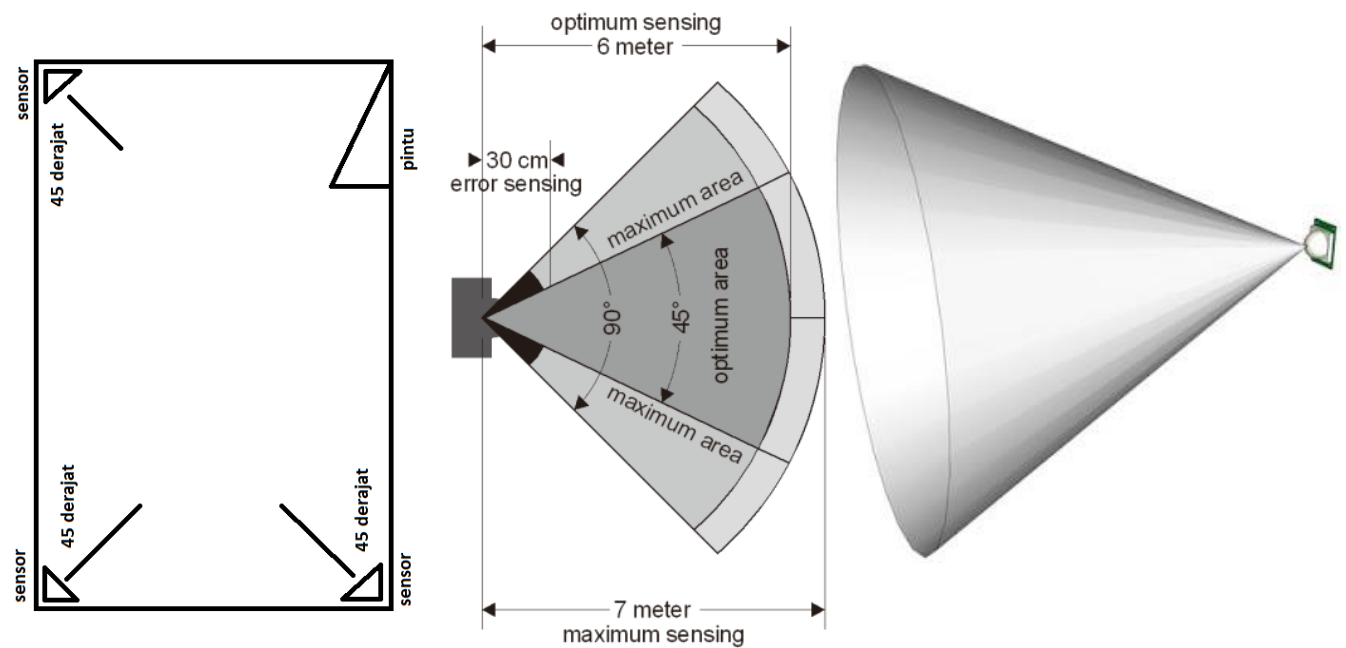

Gambar 5. Ruang Ukur Sensor Gerak di R. Kelas UNTAR (7 m x 7 m) \& Pola Sensor Gerak

\section{HASIL REALISASI DI SMPN 02 CIBINONG}

Pada rancangan realisasi dilakukan pada ruangan di kelas sekolah SMPN 02 Cibinong. Pada Gambar 1. Ruangan berukuran 9x7 $\mathrm{m}^{2}$ sehingga penempatan sensor sebanyak 7 pcs sensor gerak. Menurut dari hasil desain peletakan sensor agar pembacaan nya menjadi cukup akurat. Desain penempatan sensor akan ditempatkan pada Gambar 6. Dimana ruangan akan seakan dibagi menjadi 2 posisi pembacaan yaitu bagian depan dan belakang. Pada desain ruangan ditambahkan sebuah kendali manual apabila sensor tidak bekerja dengan baik (Panofsky \& Phillips, 1961), maka kendali manual harus dinyalakan untuk mematikan sensor. Dan sepenuhnya sistem akan kembali seperti manual. Diharapkan sistem ini berhasil sehingga dapat membuat suatu pemodelan perilaku baru di masyarakat. Diagram lajur pengkabelan agar terdapat 2 buah metode yaitu dengan manual dan sistem otomatis, maka dibuat desain jalur pengkabelan seperti pada Gambar 7 . Digunakan 2 buah saklar tambahan untuk mengendalikan atau memutuskan sistem otomatis dan menggunakan saklar manual apabila sistem sensor gerak memiliki masalah.

Dalam realisasi nya dengan menggunakan grouping sensor akan lebih efektif untuk pemasangan ruang kelas yang tidak digunakan seluruh bagian kelas. Sehingga tidak semua lampu menyala semua. Hal ini mempertimbangkan dan mengikuti kebiasaan dalam penggunaan kelas tersebut. Pengelompokan ruang kelas menjadi 2 bagian hingga 3 bagian dapat menambah penghematan energi pada ruangan tersebut. Menggunakan sensor otomatisasi nyala lampu ini tentunya memudahkan manusia agar tidak lupa mematikan saklar lampu pada ruangan ketika tidak digunakan. 


\section{KESIMPULAN}

Pada sistem diperlukan sistem manual dan otomatis dimana untuk membiasakan diri dengan teknologi diperlukan waktu dan sistem manual tetap dapat membantu manusia memiliki kebiasaan mandiri dalam penghematan energi. Teknologi otomatis hanya membantu apabila perilaku manusia tersebut tidak berubah lebih baik dalam memberikan budidaya penghematan energi. Sistem ini akan membantu dalam menghemat energi dalam lingkungan yang tidak saling peduli, umumnya di tempat umum. Hal ini dapat menciptakan harmonisasi antara teknologi dan perilaku manusia untuk menciptakan budaya hemat energi bersama.

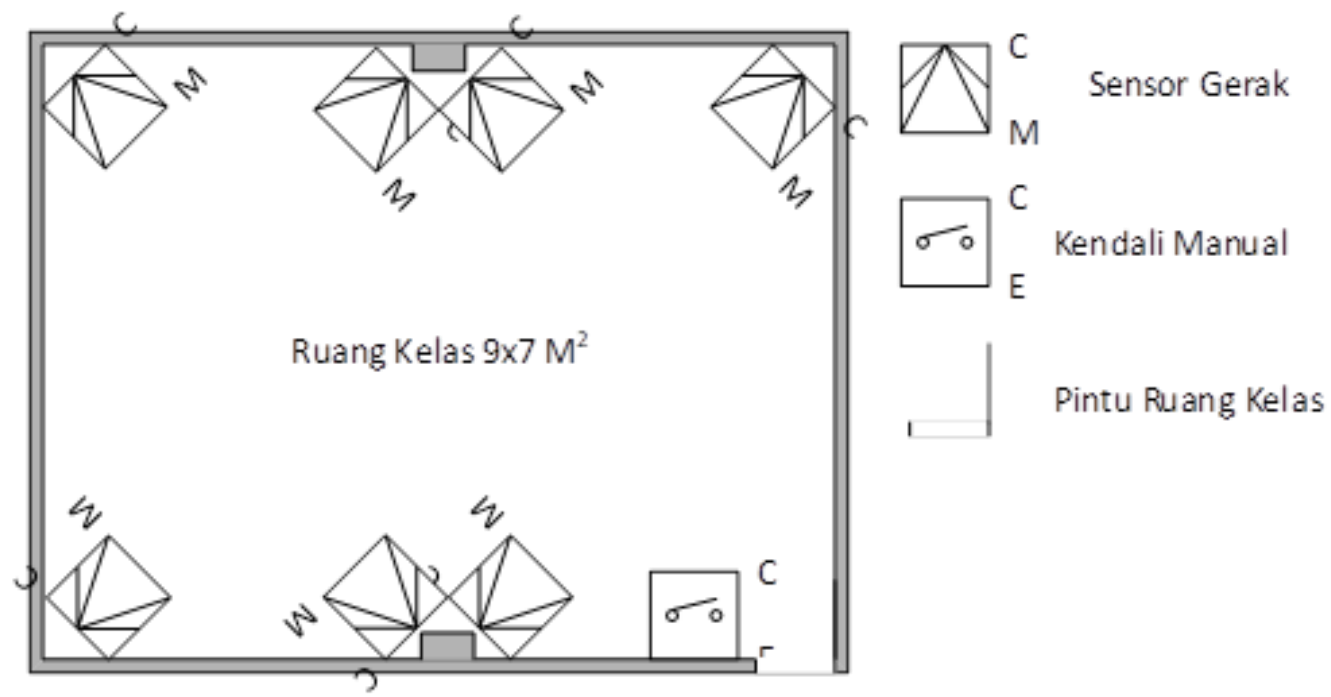

Gambar 6. Desain untuk Penempatan sensor di Ruang Kelas SMPN 02 Cibinong

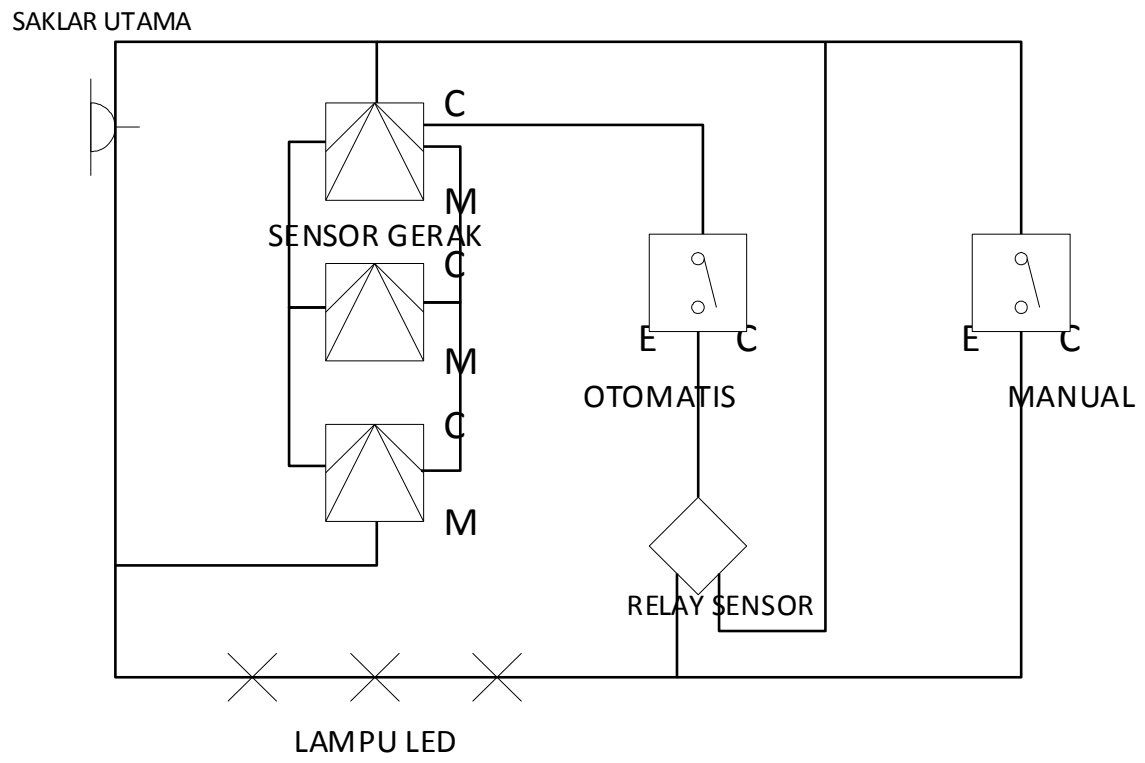

Gambar 7. Jalur Pengkabelan dengan 2 saklar otomatis dan manual 


\section{Ucapan Terima Kasih}

Terima kasih kepada Lembaga Penelitian dan Pengabdian kepada Masyarakat yang telah memberikan pendampingan untuk kegiatan yang diadakan oleh dikti untuk SMPN 02 Cibinong. Terima kasih juga diucapkan untuk Himpunan Teknik Iluminasi Indonesia yang membantu serta mencarikan untuk donatur dan sebagai wadah komunikasi serta inkubasi teknologi perlampuan di Indonesia.

\section{REFERENSI}

Badan Standardisasi Nasional. (2000). SNI 03-6197-2000 Konservasi energi pada sistem pencahayaan. Sni 03-6197-2000, 17.

DiLaura DL, Houser KW, Mistrick RG, S. G. (2011). The lighting handbook reference and application. In The lighting handbook reference and application. New York (NY): Illuminating Engineering Society of North America. 1328 p.

Fraden, J. (2016). Handbook of Modern Sensors. In Handbook of Modern Sensors. https://doi.org/10.1007/978-3-319-19303-8

Panofsky, W. K. ., \& Phillips, M. (1961). Classical electricity and magnetism. In Addison-Wesley (2nd ed.). Addison-Wesley Publishing Company, INC.

Widodo, L., Dewi, F. I. R., \& Setyaningsih, E. (2015). Ergonomic Aspect of Physical Environment in Junior High School (Between Individual Comfort and Saving Energi Behavior). Conference: 2nd International Conference on Engineering of Tarumanagara (ICET), 2.

Wilson, J. S. (2005). Sensor Technology Handbook by Jon S. Wilson (z-lib.org).pdf. 